\title{
A Modified Computing Algorithm for Raking Ratio Estimation Subject to Partial Marginal Information
}

\author{
Chang Kyoon, Son ${ }^{1)}$
}

\begin{abstract}
We suggest the modified computing algorithm for raking ratio estimation under the assumption that the population total is partially known, and the sample total is completely known about survey variable in contingency table. We show that the proposed estimation procedure is useful to estimate the population cell count in this situation through an empirical study.
\end{abstract}

Keywords : Raking ratio estimation, Population marginal count, Partial information, Weighting adjustment.

\section{1. 서론}

래킹비 추정과정은 Deming과 Stephan(1940)에 의해 iteration proportional fitting(:IPF) 라는 반 복적인 방법으로 처음 소개되었고, 이 방법은 모집단의 칸수에 대한 2개 이상의 주변분포에 대해 동시에 비(ratio)를 수정하는 것이다. 이것은 기지의 주변 모집단 총합을 이용하여 칸 가중 값올 래킹 (raking) 함으로서 래킹비를 추정하는 방법이다.

래킹비 추정과 관련하여 많은 연구가 진행되어오고 있지만, 공통적으로 래킹비 추정의 장점으로 는 2 차원 이상의 분할표에서 칸수가 미지이거나, 매우 작은 칸에 대해 효율적인 추정이 가능하다 는 점이다( Brackstone과 Rao, 1979; Causey,1972; Oh와 Schurern,1987,1989). 만일 분할표 상에서 모집단 칸수가 기지이고 그에 따른 표본칸수가 적절히 크다면, 가중값 조정은 사후층화 추정이 될 수 있다.

그러나 이와 같은 경우는 일반적으로 드물게 발생하기 때문에 표본칸수에 대해 래킹 방법을 적 용한 추정을 수행하게 되며, 특별히 이용가능한 정보가 극히 제한적인 경우 기존의 래킹 추정방법 으로는 추정이 곤란한 경우가 발행한다.

또한 분할표 상의 톡정 표본칸수가 0 인 경우 래킹 추정과정은 수렴하지 않을 수 있다는 단점을 가지지만, 이러한 경우 0이 아닌 다른 칸들과의 칸 결합을 통해 수렴성 문제를 해결할 수 있다 (Lohr,1999).

이와 같은 문제와 관련하여, 모집단 정보는 제한적인 반면에 이용 가능한 표본정보가 완전할 때

1) Full-time Lecturer, Division of Liberal Art \& Science, Hyupsung University, Kyonggido, 420-714, Korea

E-mail : ckson85@hyupsung.ac.kr 
기존의 래킹비 추정방법을 수정한 새로운 추정방법이 요구되었다. 즉, 모집단 정보로 이용 가능한 자료는 조사단위에 대해 우편번호, 성별, 교육수준등과 같은 부분적인 정보인 반면 표본자료는 해 당 조사단위에 대해 소득, 취업상태, 소비액 등 많은 정보를 포함하고 있는 경우 보다 많은 보조 정보를 추정과정에 적용할 수 있을 것이다.

본 논문에서는 이러한 상황에 대해 전통적인 래킹비 추정(typical raking ratio estimation: TRRE)방법을 수정하여 부분적인 정보를 이용한 래킹비 추정(partial raking ratio estimation: PRRE)방법을 제안하고, 실제 자료를 이용하여 제안한 방법의 실용성에 대해 살펴보자 한다.

논문의 구성으로는 먼저 2절에서는 기존의 TRRE 대해 언급하였고, 3 절에서는 본 논문에서 제 안한 PRRE를 다루었으며, 4절에서는 실제 자료를 이용한 PRRE 추정과정을 단계별로 설명하였 고, 또한 모의자료를 이용하여 효율성을 살펴보았고, 5 절에서는 결론부분을 다루었다. 부록에는 4 절에 설명한 $\mathrm{PREE}$ 추정과정을 적용한 표를 실었다.

\section{2. 전통적인 래킹비 추정과정(TRRE)}

일반적으로. 래킹비 추정과정은 관심변수와 강한 상관관계를 갖는 보조변수의 기지의 모집단 주 변총합을 이용하게 된다. 이때, 이용 가능한 보조변수로는 전수조사 자료나 단계별조사의 경우 이 전 단계에서 추정한 자료가 될 수 있다.

래킹비 추정과정을 설명하기 위해 우선, $U$ 를 모집단이라고 하면, $U$ 가 $R \times C$ 인 교차표로 분 할된다고 하자. 그러면 $U_{r c}$ 는 $(r, c)$ 칸의 크기 $N_{r c}$ 인 단위로 구성된 모집단 칸이 된다. 이때 $R$ 과 $C$ 는 각각 분할표 상의 행(row)과 열(column)의 수롤 나타내며, $r$ 과 $c$ 는 각각 행과 열을 나타낸 다. 표본을 $s$ 라 하고, 표본 칸은 $s_{r c}=s \cap U_{r c}$ 으로 표현할 수 있다. 또한 $w_{k}$ 를 단위 $k$ 의 조사 가 중값이라 하자. 관심변수를 $y$ 라 하고, 단위 $k$ 의 값은 $y_{k}$ 이며, $\sum_{k \in s} w_{k} y_{k}$ 는 모집단 총합 $\sum_{k \in U} y_{k}$ 의 추 정량이라 하자. 일반적으로 가중값 조정은 이와 같은 관심변수에 대응되는 가중값을 적절히 조정 함으로서 모집단 총합에 대한 추정량을 구할 수 있게 된다.

그러면, 래킹비 추정과정을 위해 2 차원 분할표를 고려하자. $N_{r c}$ 는 앞에서 정의한 바와 같이 $r$ 번 째 행과 $c$ 번째 열에 의해 정의되는 칸에 있는 모집단 단위들의 수이며, 미지이다. 그러나 모집단 의 행들의 합과 열들의 합인 주변 총합은 기지로서, 이들 값은 식(2.1)과 같이 정의된다.

$$
\begin{aligned}
& N_{r+}=\sum_{c=1}^{C} N_{r c}, r=1,2, \cdots, R, \\
& N_{+c}=\sum_{r=1}^{R} N_{r c}, c=1,2, \cdots, C
\end{aligned}
$$

미지의 모집단 칸수 $N_{r c}$ 는 다음과 같은 과정을 통해 표본으로부터 추정된다. 먼저 조사 가중값 $w_{0}=N / n$ 으로부터 출발한다. 이때 $N=\sum_{r}^{R} \sum_{c}^{C} N_{r c}$ 은 모집단의 크기이며, $n$ 은 표본수이다. 그러면 가중값 $w_{0}$ 으로부터 기지의 모집단 주변총합을 이용하여 다음과 같이 일련의 가중값들을 조정하게 
된다.

$$
\begin{aligned}
& w^{(1,1)}=\left[\frac{N_{r+}}{\sum_{c=1}^{C} \tilde{N}_{r c}(0)}\right] \times w_{0}, \\
& w^{(1,2)}=\left[\frac{N_{+c}}{\sum_{r=1}^{R} \tilde{N}_{r c}{ }^{(1,1)}}\right] \times w^{(1,1)}
\end{aligned}
$$

식(2.2)에서 $\tilde{N}_{r c}^{(0)}$ 은 설계 가중값 $w_{0}$ 을 이용한 모집단 칸수 $N_{r c}$ 의 추정치이다. 그러면 행에 대 해 갱신된 가중값 $w^{(1,1)}$ 를 $\tilde{N}_{r c}^{(1,1)}$ 를 계산하기 위해 사용하며, 이 값은 또한 $N_{r c}$ 의 추정치가 된 다. 첫 번째 반복이 종료된 후 조정된 가중값 $w^{(1,2)}$ 를 얻게 된다. 이와 같은 반복적인 과정은 특 정한 수렴 조건은 만족할 때 까지 계속 된다.

최종적으로 조정된 가중값을 $w^{(f)}$ 라 하면, 이 값을 모집단 총합의 추정량의 식 $\sum_{k \in s} w_{k} y_{k}$ 에 적용 함으로서 추정과정을 종료하게 된다.

이러한 래킹비 추정과정을 설명하기 위해 다음과 같은 간단한 예를 들어보기로 하자.

예2.1) $R=C=2$ 라 하고, $N=700$ 인 모집단으로부터 단순임의 표본 $n=80$ 을 얻었다고 하 자. 이때, 완전응답을 가정하고 조사결과를 다음과 같은 분할표로 작성하였다.

<표 2.1> 조사결 과표

\begin{tabular}{c|c|c|c}
\hline & Yes & No & 합계 \\
\hline Group1 & 10 & 20 & 300 \\
\hline Group2 & 25 & 25 & 400 \\
\hline 합계 & 350 & 350 & 700 \\
\hline
\end{tabular}

Group1 과 Group2 의 단위들이 각각 "Yes" 와 "No"라고 응답한 수를 각 칸에 빈도수로 나타내 고, 행과 열의 주변수 합계는 모집단 정보로서 기지라 하자. 그러면 4개의 칸에 해당하는 모집단 칸수에 대한 추정올 위해 설계 가중값 $w_{0}=700 / 80=8.75$ 을 사용하여 다음과 같은 값을 구할 수 있다. 이때, 관심변수의 값은 모두 1이라 가정한다.

$$
\widetilde{N}_{r c}^{(0)}=\sum w_{k}=8.75 n_{r c}
$$

반복식 (2.2)를 이용하여 최종 가중값 $w^{(f)}$ 를 얻는 절차는 다음과 같은 단계로 표현된다.

먼저 <표 2.2>와 같이 설계가중값 (2.3)을 각 칸에 적용한 후 이 값들의 주변수 총합을 구한다. 
<표 2.2> 행에 가중값을 적용

\begin{tabular}{c|c||c}
\hline 87.5 & 175 & 262.5 \\
\hline 218.75 & 218.75 & 437.5 \\
\hline
\end{tabular}

다음으로 <표 2.1>의 열 주변수 총합을 <표 2.2>에서 구한 행 주변수 총합으로 나눈 값 $300 / 262.5$ 와 $400 / 437.5$ 를 <표 2.2 >의 각 칸에 곱하여 <표 $2.3>$ 을 얻게 된다.

<표 2.3> 열에 가중값을 적용

\begin{tabular}{c|c}
\hline 100 & 200 \\
\hline 200 & 200 \\
\hline 300 & 400 \\
\hline
\end{tabular}

이와 같은 과정으로부터 행과 열에 대한 칸 가중값 조정과정이 하나의 사이클을 형성하며, 1 단 계 반복이 끝나게 된다.

다음으로 <표 2.3>에서 첫 번째 열의 합과 두 번째 열의 합으로 각각 <표 $2.1>$ 의 첫 번째 행 과 두 번째 행의 합을 나눈 값 $350 / 300$ 과 $350 / 400$ 를 <표 $2.3>$ 의 각 칸에 곱하여 다음과 같은 <표 2.4>를 얻게 된다.

<표2.4> 행에 가중값을 적용

\begin{tabular}{l|l|l}
\hline 116.7 & 175 & 291.5 \\
\hline 233.3 & 175 & 408.3 \\
\hline
\end{tabular}

같은 방법으로 이번에는 <표 $2.3>$ 의 열들의 합을. <표 $2.4>$ 의 행들의 합으로 나눈 값 $300 / 291.5$ 과 $400 / 408.3$ 를 <표 2.4>의 각 칸에 곱하여 2 단계 반복이 끝나게 되며, <표 $2.3>$ 과 유사한 형태의 표를 얻을 수 있다.

이와 같은 과정을 6 희 반복한 후 수렴조건을 만족하여 <표 $2.4>$ 와 같은 추정된 칸수를 갖는 분 할표를 얻을 수 있다. 이때 반복 과정의 수렴조건은 다음과 같다.

$$
\left|\sum_{c} \widetilde{N}_{+c}-M\right| \times 100<0.01(\%)
$$

<표 2.4>와 같이 Group1에서 "Yes" 라고 응답한 수가 121명으로 추정되었고, Group2에서 "Yes" 라고 응답한 수는 229명으로 추정되었다.

<표 2.4> 6회 반복 후 추정된 칸 수

\begin{tabular}{c|c|c|c}
\hline & Yes & No & 합계 \\
\hline Group1 & 121 & 179 & 300 \\
\hline Group2 & 229 & 171 & 400 \\
\hline 합계 & 350 & 350 & 700 \\
\hline
\end{tabular}


만일 단순 비 추정을 적용할 경우에는 각각 87.5 명과 218.75 명으로 추정되어 과소 추정됨을 알 수 있다.

\section{3. 부분 래킹비 추정과정(PRRE)}

이 절에서는 2절에서 설명한 것과는 다르게 일부 항목에 대한 정보가 모집단수준에 대해 알려 져 있지만, 그 밖의 항목에 대해서는 표본수준에 대해 알려져 있는 경우를 다루고자 한다. 이러한 경우 전통적인 래킹비 추정과정을 적용할 수 없으며, 만일 적용한다 하더라도, 래킹 과정의 조건 에 어긋나기 때문에 수렴하지 않울 수 있다.

따라서 이와 같은 상황에 대해 2차원 분할표에서 부분적으로 모집단 행(또는 열)주변 총합이 기 지라는 조건하에서 래킹비 추정에 대해 수정된 알고리즘을 제안하고자 한다.

\section{1 부분 래킹비 추정과정}

2차원 분할표 상에서 부분정보 즉, 하나의 항목에 대해서는 모집단과 표본 수준에 대해 주변 수 를 알 수 있는 반면에 나머지 항목에 대해서는 표본수준의 정보만을 알 수 있는 경우이다. 이를 2 차원 분할표로 나타내면 다음의 <표 3.1>과 같이 표현할 수 있다.

<표 3.1> 행 변수에 대해 모집단 주변수가 기지인 경우

\begin{tabular}{c|c|c|c|c||c}
\hline & Col $_{1}$ & Col $_{2}$ & $\cdots$ & $C_{C} l_{C}$ & 합 계 \\
\hline$R o w_{1}$ & $n_{11}$ & $n_{12}$ & $\cdots$ & $n_{1 C}$ & $N_{1}$ \\
\hline$R o w_{2}$ & $n_{21}$ & $n_{22}$ & $\cdots$ & $n_{2 C}$ & $N_{2}$ \\
\hline$\ldots$ & $\cdots$ & $\cdots$ & $\cdots$ & $\cdots$ & $\cdots$ \\
\hline$R o w_{R}$ & $n_{R 1}$ & $n_{R 2}$ & $\cdots$ & $n_{R C}$ & $N_{R}$ \\
\hline \hline 합계 & $n_{+1}$ & $n_{+2}$ & $\cdots$ & $n_{+C}$ & $N$ \\
\hline
\end{tabular}

<표 3.1>로부터 행과 열변수의 항목들은 각각 $R o w_{1}, \operatorname{Row}_{2}, \cdots, \operatorname{Row}_{R}$ 와 각각 $\operatorname{Col}_{1}, \operatorname{Col}_{2}, \cdots$, $\mathrm{Col}_{C}$ 으로 표현하였다. 또한 $n_{r c}$ 은 표본수준에 대해 행과 열변수를 교차하여 얻은 표본 칸 수를 나 타낸다. $N_{r}$ 은 주변수 총합들 중 행 변수에 대해 $r$ 번째 행의 모집단 주변 수를 나타내며, $n_{+c}$ 은 $c$ 번째 열에 대해 표본수준에서 열변수의 주변수 총합을 나타낸다.

이와 같이 부분적인 정보로 이루어진 분할표는 표본수준에서 얻은 도수분포표와 모집단 수준에 얻은 도수분표를 동일한 변수에 대해 교차시켜 얻을 수 있다. 물론 행과 열변수의 항목수와 관련 하여, 분류항목의 수는 표본과 모집단 수준에서 동일해야 하며, 적어도 모집단과 표본수준에서 이 용 가능한 변수는 동일한 수준으로 분류되어야 한다.

전통적인 래킹비 추정과정을 적용하여 모집단 행의 주변수 총합올 이용하여 구한 열의 주변수 총합을 의사-열주변모집단총합(pseudo-column marginal population total), $\widetilde{N}_{+c}$ 이라 하자. 이때 
$\widetilde{N}_{+c}=\sum_{r=1}^{R} \widetilde{N}_{r c}, c=1,2, \cdots, C$ 이다. 이 값을 구하기 위한 과정은 다음의 절차에 의해 수행된다. $R \times C$ 칸에 대해 설계 가중 값 $w_{0}=N / n$ 을 곱하여 다음과 같은 표를 얻을 수 있다.

<표 $3.2>$ 각 칸에 설계가중값을 곱함

\begin{tabular}{c|c|c|c|c||c}
\hline & $C o l_{1}$ & $\operatorname{Col}_{2}$ & $\cdots$ & $C o l_{C}$ & 합계 \\
\hline Row $_{1}$ & $n_{11} \times w_{0}$ & $n_{12} \times w_{0}$ & $\cdots$ & $n_{1 C} \times w_{0}$ & $\tilde{n}_{1+}^{(0)}$ \\
\hline $\operatorname{Row}_{2}$ & $n_{21} \times w_{0}$ & $n_{22} \times w_{0}$ & $\cdots$ & $n_{2 C} \times w_{0}$ & $\tilde{n}_{2+}^{(0)}$ \\
\hline$\ldots$ & $\ldots$ & $\cdots$ & $\cdots$ & $\cdots$ & $\cdots$ \\
\hline$R o w_{R}$ & $n_{R 1} \times w_{0}$ & $n_{R 2} \times w_{0}$ & $\cdots$ & $n_{R C} \times w_{0}$ & $\tilde{n}_{R+}^{(0)}$ \\
\hline
\end{tabular}

여기서 주변수 합계는 $\tilde{n}_{1+}^{(0)}=n_{1+} \times w_{0}, \tilde{n}_{2+}^{(0)}=n_{2+} \times w_{0}, \cdots, \tilde{n}_{R+}^{(0)}=n_{R+} \times w_{0}$ 이다.

다음으로 첫 번째 행에 대해 $N_{1} \tilde{n}_{1+}^{(0)}$ 을 곱하고, 두 번째 행에 대해 $N_{2} \tilde{n}_{2+}^{(0)}$ 를 곱한다. 같은 방 법으로 나머지 행에 대해서도 같은 절차를 수행한다. 그러면 행에 대한 가중값 조정절차로부터 다 음의 표를 얻을 수 있다.

<표 3.3> 행에 대한 주변수 총합의 비율 $\left(N_{r} \tilde{n}_{r+}\right)$ 을 각 셀에 곱함

\begin{tabular}{c|c|c|c|c}
\hline & $\operatorname{Col}_{1}$ & $\operatorname{Col}_{2}$ & $\cdots$ & $\operatorname{Col}_{C}$ \\
\hline$R o w_{1}$ & $n_{11} \times w^{(1,1)}$ & $n_{12} \times w^{(1,1)}$ & $\cdots$ & $n_{1 C} \times w^{(1,1)}$ \\
\hline$R o w_{2}$ & $n_{21} \times w^{(1,1)}$ & $n_{22} \times w^{(1,1)}$ & $\cdots$ & $n_{2 C} \times w^{(1,1)}$ \\
\hline$\cdots$ & $\cdots$ & $\cdots$ & $\cdots$ & $\cdots$ \\
\hline$R o w_{R}$ & $n_{R 1} \times w^{(1,1)}$ & $n_{R 2} \times w^{(1,1)}$ & $\cdots$ & $n_{R C} \times w^{(1,1)}$ \\
\hline \hline 합계 & $\sum_{r=1}^{R} n_{r 1} w^{(1,1)}$ & $\sum_{r=1}^{R} n_{r 2} w^{(1,1)}$ & $\cdots$ & $\sum_{r=1}^{R} n_{r} w^{(1,1)}$ \\
\hline
\end{tabular}

이와 같은 과정을 열에 대해서도 수행하여 1 차 반복이 완료되며, 이를 요약하면 다음과 같이 표 현할 수 있다. 즉, 행에 대해

이고, 열에 대해

$$
w^{(1,1)}=\left(\frac{N_{r}}{\sum_{c=1}^{C} \tilde{n}_{r c}^{(0)}}\right) w_{0}, \quad r=1,2, \cdots, R,
$$

$$
w^{(1,2)}=\left(\frac{n_{+c}}{\sum_{r=1}^{R} \tilde{n}_{r c}^{(1,1)}}\right) w^{(1,1)}, \quad c=1,2, \cdots, C
$$

이다. 
행과 열에 따른 멈춤 조건을 만족할 때 까지 일정회수의 반복 후에 열의 주변수 총합은 $\widetilde{N}_{+c}=\sum_{r=1}^{R} \tilde{N}_{r c}, c=1,2, \cdots, C$ 으로 조정되지만, 행의 주변수 총합은 원래의 모집단 행의 주변수 총합과는 일치하지 않는다. 따라서 이와 같은 과정이 수렴하기 위해서는 열의 주변수 총합에 대한 특정한 멈춤 조건이 필요하게 된다. 즉, 전통적인 래킹비 추정과정과는 다르며, 여기서는 의사-열 주변수 촣합을 미지의 주변수 총합 대신 사용하게 된다. 따라서 다음과 같은 멈춤 조건을 고려할 수 있다.

$$
\left|\sum_{c=1}^{C} \widetilde{N}_{+c}-N\right| \times 100<\epsilon(\%), r=1,2, \cdots, R,
$$

여기서 $\epsilon$ 는 $(0,1)$ 의 임의의 양의 실수로서 0.01 로 고려한다.

이와 같은 멈춤 과정을 만족할 때 까지 래킹 과정을 반복함으로서 다음과 같이 원래의 분할표 상의 열 주변수 총합이 조정된 새로운 분할표를 얻게 된다. 이때, 행의 주변수 총합은 $N_{1+}, N_{2+}, \cdots, N_{R+}$ 이며, 열의 주변수 총합은 $\widetilde{N}_{+1}, \widetilde{N}_{+2}, \cdots, \widetilde{N}_{+C}$ 가 된다.

지금까지의 반복과정은 기지의 모집단 행 주변수를 이용하여 열의 주변수 총합을 조정하기 위 한 것이며, 열의 주변수 총합이 적절히 조정되었다면, 다음으로 2절에서 언급한 바와 같은 전통적 인 래킹비 추정과정을 표본 칸수의 조정을 위해 수행하게 된다.

이때 반복과정은 다음과 같이 수행된다. 행들에 대해서는

$$
w^{(1,1)}=\left[\frac{N_{r+}}{\sum_{c=1}^{C} \tilde{N}_{r c}{ }^{(0)}}\right] \times w_{0},
$$

이며, 열들에 대해서는

$$
w^{(1,2)}=\left[\frac{\tilde{N}_{+c}}{\sum_{r=1}^{R} \tilde{N}_{r c}(1,1)}\right] \times w^{(1,1)}
$$

을 수행한다.

〈표 3.4> 의사-열 주변수 총합

\begin{tabular}{c|c|c|c|c|c}
\hline & Col $_{1}$ & Col $_{2}$ & $\cdots$ & $C_{C}$ & 합계 \\
\hline$R o w_{1}$ & $n_{11}$ & $n_{12}$ & $\cdots$ & $n_{1 C}$ & $N_{1+}$ \\
\hline$R o w_{2}$ & $n_{21}$ & $n_{22}$ & $\cdots$ & $n_{2 C}$ & $N_{2+}$ \\
\hline$\cdots$ & $\cdots$ & $\cdots$ & $\cdots$ & $\cdots$ & $\cdots$ \\
\hline$R o w_{R}$ & $n_{R}$ & $n_{R 2}$ & $\cdots$ & $n_{R C}$ & $N_{R+}$ \\
\hline 합계 & $\widetilde{N}_{+1}$ & $\widetilde{N}_{+2}$ & $\cdots$ & $\widetilde{N}_{+C}$ & $N$ \\
\hline
\end{tabular}

여기서 $w_{0}=N / n$ 이고, $w^{(1,1)}, w^{(1,2)}$ 은 각각 1 단계에서 행과 열들에 대해 조정된 가중값이다.

이와 같은 과정올 일반적인 반복식으로 표현하기위해, $w_{i}^{(t, 1)}$ 과 $w_{i}^{(t, 2)}, t=1,2, \cdots, T$ 를 $t$-번째 
426 Chang Kyoon, Son

반복에 대해 행과 열의 조정된 가중값이라 하자. 그러면 조정된 가중값은 다음과 같이 표현할 수 있다. 행과 열에 대해 각각

$$
\begin{aligned}
& w_{i}^{(t, 1)}=\left(\frac{N_{r+}}{\sum_{c=1}^{C} \widetilde{N}_{r c}{ }^{(t-1,2)}}\right) \times w_{i}^{(t-1,2)}, \quad r=1,2, \cdots, R, i \in r, \\
& \tilde{w}_{i}^{(t, 2)}=\left(\frac{\widetilde{N}_{+c}}{\sum_{r=1}^{R} \tilde{N}_{r c}^{(t, 1)}}\right) \times \tilde{w}_{i}^{(t, 1)} \quad, \quad c=1,2, \cdots, C, i \in c
\end{aligned}
$$

이다.

만일 $T$ 를 총 반복수라 하면, 최종적으로 조정된 가중값은 $w_{i}^{(T, 2)}$ 가 된다. 이때, 반복은 다음과 같은 멈춤 과정을 만족할 때까지 계속된다.

$$
\left|1-\frac{\sum_{c=1}^{C} \widetilde{N}_{r+}}{N_{r+}}\right| \times 100<\epsilon(\%),
$$

또는

$$
\left|1-\frac{\sum_{r=1}^{R} \widetilde{N}_{r c}}{\widetilde{N}_{+c}}\right| \times 100<\epsilon(\%) .
$$

그러면, 2 차원 분할표상에서 부분적으로 기지인 모집단 주변 수 총합 하에서 수행된 래킹 추정 과정의 수렴성을 알아보기 위해 다음의 정리를 도입하기로 한다. 이 성질로부터 의사-열 주변수 총합을 도입한 분할표로부터 전통적인 래킹과정올 적용했을 때 의사-열 주변수의 총합이 기지의 모집단 촣합과 일치하는지를 검토하여 수렴성을 진단할 수 있을 것이다.

정리 3.1] 기지의 행 주변수 총합과 조정된 열 주변수 총합을 가진 2차원 분할표에 대해 표본 칸수의 조정을 위해 TRRE를 수행하였다면, 의사-열(또는 행) 주변수 총합 $\widetilde{N}_{+1}, \widetilde{N}_{+2}, \cdots, \widetilde{N}_{+C}$ 들의 합 $\sum_{c=1}^{C} \widetilde{N}_{+c}, r=1,2, \cdots, R$ 은 반복수 $t=1,2, \cdots, T$ 에 대해 모집단 총합 $N$ 으로 수렴한다. 즉, 다음과 같은 관계가 성립한다.

$$
\lim _{t \rightarrow \infty} \sum_{c=1}^{C} \widetilde{N}_{+c}^{(t, 1)} \approx N
$$

중명] 조정된 주변수 총합과 원래의 주변수 총합을 가진 분할표상의 TREE 과정의 수렴성을 알 아보기 위해 식(3.4)를 다음과 같이 표현할 수 있다.

$$
\tilde{N}_{r c}^{(t)}=\tilde{N}_{r c}^{(0)} \tilde{\alpha}_{r}^{(t)} \tilde{\beta}_{c}^{(t)}, t=1,2,3, \cdots
$$

여기서 행 가중값은 
이며, 열 가중값은

$$
\tilde{\alpha}_{r}^{(t)}=\prod \frac{N_{r+}}{\sum_{c=1}^{C} \tilde{N}_{r c}{ }^{(t)}}
$$

$$
\tilde{\beta}_{c}^{(t)}=\prod \frac{\widetilde{N}_{+c}}{\sum_{r=1}^{R} \widetilde{N}_{r c}^{(t)}}
$$

이다. 만일 전통적인 TREE과정이 수렴한다면, 다음과 같이 수렴 해를 구할 수 있을 것이다.

$$
\begin{aligned}
\widetilde{N}_{r c} & =\lim _{t \rightarrow \infty} \widetilde{N}_{r c}{ }^{(t)} \\
& =\widetilde{N}_{r c}^{(0)} \lim _{t \rightarrow \infty} \tilde{\alpha}_{r}{ }^{(t)} \lim _{t \rightarrow \infty} \tilde{\beta}_{c}{ }^{(t)} \\
& =\widetilde{N}_{r c}^{(0)} \tilde{\alpha}_{r} \tilde{\beta}_{c}
\end{aligned}
$$

이때 조정된 칸 수 $\widetilde{N}_{r c}$ 가 수렴한다면, 의사-열 주변수 총합 $\tilde{N}_{+1}, \widetilde{N}_{+2}, \cdots, \widetilde{N}_{+C}$ 또한 수렴하 며, 이들의 합은 결과적으로 TREE의 가정에 따라 모집단 총합 $N$ 으로 수렴한다. 참고로 이와 같 은 수렴성은 식(3.2)와 같이 멈춤 조건으로 사용될 수 있다.

\section{4. 자료를 이용한 PRRE 추정과정}

\section{1 실제 자료를 이용한 PRRE 추정과정}

이 절에서는 실제 자료를 이용하여 PRRE과정을 설명하고자 한다. 물론 일정 회수의 반복후 TRRE과정이 수렴함을 가정한다. 이에 대한 타당성은 이미 3절에서 설명한바 있다.

$\mathrm{PREE}$ 를 적용할 자료로는 한국산업안전공단(KOSHA)에서 수행한 산업재해 조사 자료로서 추출 틀은 근로복지공단(KLWC)에 의해 분류된 재해자들로 구성된다.

추정의 목적은 재해자 모집단으로부터 표본을 추출하여, 재해원인별, 산업별 자해자수를 추정하 고자 한다. 그러나 이용 가능한 정보는 단지 산업형태별 모집단 주변수이며, 따라서 표본조사 자 료만을 이용할 경우 기본적인 비 추정만이 가능하지만, 앞의 2절에 언급한 바와 같이 전통적인 비 추정 표본분할표상에 적용할 경우 재해자 모집단 칸수를 과소추정하게 되며, 결과적으로 왜곡된 산업재해정책이 수립될 위험이 크게 된다. 이와 같은 이유로 전통적인 비 추정을 배제하고, 제한 적으로 알려진 모집단 정보롤 최대한 이용함으로서 과소추정의 위험성을 제거하고자 PRRE 과정 올 적용하였다. 우선 알려진 모집단 정보로서 산업 형태별 분류중 산업 대분류를 적용하고, 제조 업의 경우 중분류를 적용한 35가지 산업분류변수를 이용하였다. 이 정보는 표본 재해자 파일에 존 재하는 유일한 모집단 정보이다. 산업 중분류와 관심변수(재해원인, 작업내용, 기인물, $\cdots$ 등)간에 2 차원 분할표를 작성한 후 적용하여 관심변수에 대한 의사-열(또는 행)주변수 총합을 구한 후, 이 값을 원래의 표본분류표의 열 또는 행의 주변수 총합에 적용하여 전통적인 래킹비 추정과정을 통 해 각 분류에 대한 모집단 총합을 구할 수 있다. 2001년 조사 자료로부터 <부록 표 1>과 같이 
“산업분류×재해원인"에 대한 표본 분류표를 작성하였다. 이때 표본은 전체 재해자수 모집단 $N=73,529$ 으로부터 $n=7,217$ 인 계통표본으로 추출한 자료이다.

논문에서 제안한 추정과정을 단계별로 요약하면 다음과 같다.

첫 번째 단계에서 <부록 표 1 >과 같이 표본자료를 이용하여 “산업분류(35개 항목)×재해원인(12 개 항목)"에 따른 2 차원 분할표를 작성한다. 이때 산업분류와 함께 사용되는 행(또는 열) 변수는 다른 항목에 대해서도 적용할 수 있으며, 실제 추정하고자하는 변수를 적용한다.

두 번째 단계에서는 <부록 표 2 >와 같이 분할표상에서 부분적으로 기지인 모집단 주변 수 총 합을 산업분류에 따라 재배치한다. 모집단의 분류항목은 표본의 분류항목과 일치해야한다.

세 번째 단계에서는 <부록 표 3 >과 같이 3 절에서 설명한 PRRE 과정을 수행하여 표본변수에 대한 열 주변수 총합에 대한 추정값 즉, 의사-열 주변수 총합을 얻는다. 이 과정에서 조정된 분할 표상의 칸들의 값은 무시한다.

네 번째 단계에서는 새롭게 구해진 의사-열 주변수 총합과 기지의 행 주변수 총합을 표본 분할 표에 적용한 2 차원 분할표를 재 작성한다.

마지막 단계에서는 이전 단계에서 얻은 분할표를 이용하여 TRRE과정을 수행하여 <부록 표 4> 와 같이 최종적으로 모집단 칸수를 추정한다.

특별히 서론에서 언급한 $\operatorname{Lohr}(1999)$ 의 지적과 같이 특정한 칸의 값이 0인 경우 래킹비 추정 과 정이 수렴하지 않을 수 있다는 점은 래킹비 추정과정을 적용할 경우 항상 염두에 두어야할 사항 이지만, 본 논문의 경우 수렴성에는 아무런 문제가 되지 않았음올 밝혀둔다.

\section{2 모의 자료를 이용한 PRRE 추정과정}

이 절에서는 PRRE 추정과정올 적용했을 때, 모집단 칸수를 어떻게 추정하는지를 알아보기 위 해 모의자료를 이용하였다. 이를 위해 가장 간단한 방법으로 열 변수와 행 변수에 대해 다음과 같 은 $N=12,000$ 개의 가상 모집단을 발생시켰다.

$$
x_{i} \sim U(0,1), z_{i} \sim U(0,1)
$$

이때, 모집단은 먼저 열 변수로 적용하기 위해 다음과 같은 기준으로 분할한다.

$$
X_{1}: 0 \leq x_{i}<0.2, X_{2}: 0.2 \leq x_{i}<0.4, X_{3}: 0.4 \leq x_{i}<0.6, X_{4}: 0.6 \leq x_{i}<0.8, X_{5}: 0.8 \leq x_{i} \leq 1
$$

다음으로 행 변수를 적용하기 위해 다음과 같은 기준으로 분할한다.

$$
Z_{1}: 0 \leq z_{i}<0.3, Z_{2}: 0.3 \leq z_{i}<0.6, Z_{3}: 0.6 \leq z_{i} \leq 1
$$

이와 같은 과정으로부터 가상 모집단에 대한 분할표는 다음과 같다. 이때 모집단 칸수는 미지라 고 가정한다.

<표 4.1> 모집단 분할표

\begin{tabular}{r|r|r|r|r|r|r}
\hline & \multicolumn{1}{|c|}{$X_{1}$} & \multicolumn{1}{|c|}{$X_{2}$} & \multicolumn{1}{|c|}{$X_{3}$} & \multicolumn{1}{|c|}{$X_{4}$} & \multicolumn{1}{c|}{$X_{5}$} & \multicolumn{1}{|c}{ 합 계 } \\
\hline$Z_{1}$ & 742 & 737 & 679 & 704 & 687 & 3,549 \\
\hline$Z_{2}$ & 703 & 721 & 764 & 741 & 727 & 3,656 \\
\hline$Z_{3}$ & 927 & 952 & 938 & 987 & 991 & 4,795 \\
\hline 합 계 & 2,372 & 2,410 & 2,381 & 2,432 & 2,405 & 12,000 \\
\hline
\end{tabular}


모집단 칸수에 대한 추정 절차는 앞에서 다룬 바와 같이 먼저 모집단으로부터 단순임의 추출설 계를 적용하여 $n=1200$ 개의 단순임의표본을 추출하여 이들에 대한 표본 분할표를 다음과 같이 작성하였다.

<표 4.2> 표본 분할표

\begin{tabular}{c|r|r|r|r|r|r}
\hline & $X_{1}$ & $X_{2}$ & $X_{3}$ & $X_{4}$ & \multicolumn{1}{|c|}{$X_{5}$} & 합 계 \\
\hline$Z_{1}$ & 76 & 82 & 89 & 59 & 70 & 376 \\
\hline$Z_{2}$ & 60 & 86 & 76 & 81 & 74 & 377 \\
\hline$Z_{3}$ & 70 & 83 & 91 & 105 & 98 & 447 \\
\hline 합 계 & 206 & 251 & 256 & 245 & 242 & 1,200 \\
\hline
\end{tabular}

다음으로 표본분할표상의 칸수와 행들의 주변수 총합만을 이용하여 PRRE를 적융하기 위해 다 음과 같은 분할표를 작성할 수 있다.

<표 4.3> 표본 분할표에 기지의 모집단 행 주변수 총합을 결합한 표

\begin{tabular}{c|r|r|r|r|r|r}
\hline & $X_{1}$ & \multicolumn{1}{|c|}{$X_{2}$} & $X_{3}$ & $X_{4}$ & \multicolumn{1}{|c|}{$X_{5}$} & 합 계 \\
\hline$Z_{1}$ & 76 & 82 & 89 & 59 & 70 & $\mathbf{3 , 5 4 9}$ \\
\hline$Z_{2}$ & 60 & 86 & 76 & 81 & 74 & $\mathbf{3 , 6 5 6}$ \\
\hline$Z_{3}$ & 70 & 83 & 91 & 105 & 98 & $\mathbf{4 , 7 9 5}$ \\
\hline 합 계 & 206 & 251 & 256 & 245 & 242 & $\mathbf{1 2 , 0 0 0}$ \\
\hline
\end{tabular}

<표 4.3>에 PRRE 과정올 적용하여 다음과 같이 의사-열 주변수 총합을 구한다.

<표 4.4> PRRE를 적용하여 구한 의사-열 주변수 충합

\begin{tabular}{r|r|r|r|r|r|r}
\hline & $X_{1}$ & \multicolumn{1}{|c|}{$X_{2}$} & \multicolumn{1}{|c|}{$X_{3}$} & $X_{4}$ & \multicolumn{1}{c|}{$X_{5}$} & 합 계 \\
\hline$Z_{1}$ & 76 & 82 & 89 & 59 & 70 & 3,549 \\
\hline$Z_{2}$ & 60 & 86 & 76 & 81 & 74 & 3,656 \\
\hline$Z_{3}$ & 70 & 83 & 91 & 105 & 98 & 4,795 \\
\hline 합 계 & $\mathbf{2 , 0 5 0 . 1 0 2 7}$ & $\mathbf{2 , 4 9 8 . 3 2 5 5}$ & $\mathbf{2 , 5 5 3 . 2 3 7 7}$ & $\mathbf{2 , 4 6 8 . 7 3 9 9}$ & $\mathbf{2 , 4 2 9 . 5 9 4 2}$ & 12,000 \\
\hline
\end{tabular}

마지막으로 <표 4.4>을 이용하여 TRRE를 적용하여 추정한 모집단 칸수는 다음과 같다. 
<표 4.5> TRRE를 적용하여 구한 모집단 칸수 추정 값

\begin{tabular}{c|r|r|r|r|r|r}
\hline & \multicolumn{1}{|c|}{$X_{1}$} & \multicolumn{1}{c|}{$X_{2}$} & \multicolumn{1}{c|}{$X_{3}$} & \multicolumn{1}{c|}{$X_{4}$} & \multicolumn{1}{c|}{$X_{5}$} & 합 계 \\
\hline$Z_{1}$ & $\mathbf{7 1 7 . 3 5 1 0 7}$ & $\mathbf{7 7 3 . 9 8 4 0 4}$ & $\mathbf{8 4 0 . 0 5 5 8 4}$ & $\mathbf{5 5 6 . 8 9 0 9 6}$ & $\mathbf{6 6 0 . 7 1 8 0 8}$ & 3,549 \\
\hline$Z_{2}$ & $\mathbf{5 8 1 . 8 5 6 7 7}$ & $\mathbf{8 3 3 . 9 9 4 7}$ & $\mathbf{7 3 7 . 0 1 8 5 6}$ & $\mathbf{7 8 5 . 5 0 6 6 4}$ & $\mathbf{7 1 7 . 6 2 3 3 4}$ & 3,656 \\
\hline$Z_{3}$ & $\mathbf{7 5 0 . 8 9 4 8 6}$ & $\mathbf{8 9 0 . 3 4 6 7 6}$ & $\mathbf{9 7 6 . 1 6 3 3}$ & $\mathbf{1 , 1 2 6 . 3 4 2 3}$ & $\mathbf{1 , 0 5 1 . 2 5 2 8}$ & 4,795 \\
\hline 합 계 & $2,050.1027$ & $2,498.3255$ & $2,553.2377$ & $2,468.7399$ & $2,429.5942$ & 12,000 \\
\hline
\end{tabular}

추정된 모집단 칸 수와 기지의 모집단 칸수 간의 상대편향을 구해본 결과 다음과 같다. 이때 상 대편향은 다음과 같이 정의된다.

$$
R E\left(\hat{N}_{i j}\right)=\left(\frac{\hat{N}_{i j}-N_{i j}}{N_{i j}}\right) \times 100 \%, i=1,2,3 ; j=1,2,3,4,5
$$

<표 4.6> PRRE에 의해 추정된 모집단 칸수에 대한 상대편향(\%)

\begin{tabular}{r|r|r|r|r}
\hline-3.32 & 5.02 & 23.72 & -20.90 & -3.83 \\
\hline-17.23 & 15.67 & -3.53 & 6.01 & -1.29 \\
\hline-19.00 & -6.48 & 4.07 & 14.12 & 6.08 \\
\hline
\end{tabular}

앞에서 전개한 $\mathrm{PRRE}$ 에 의한 상대편향과 $\mathrm{TRRE}$ 에 의한 상대편향올 비교하기위해 기지의 모집 단 주변수 총합을 이용한 TRRE의 상대편향은 다음과 같다.

<표 4.7> TRRE에 의해 추정된 모집단 칸수에 대한 상대편향(\%)

\begin{tabular}{r|r|r|r|r}
\hline 11.46 & 0.92 & 14.95 & -22.40 & -5.18 \\
\hline-4.03 & 11.80 & -9.86 & 4.58 & -2.12 \\
\hline-6.12 & -9.65 & -2.79 & 12.54 & 5.14 \\
\hline
\end{tabular}

모집단으로부터 $10 \%$ 표본을 추출하였으므로 표본 분할표에 나타난 각 칸의 추출률 또한 거의 $10 \%$ 를 유지하고 있으며, 이를 바탕으로 추정결과를 나타내는 <표 $4.5>$ 는 각 셀에 대해 표본 분 할표상의 추출률을 유지하고 있음을 나타낸다. 따라서 각 칸의 모집단 추정값은 표본 추출률만큼 의 가중값이 각 셀에 할당되었음을 의미한다.

\section{5. 결론}

일반적으로 래킹비 추정과정은 분할표상의 기지의 행과 열의 주변수 총합을 이용하여 표본칸 수를 모집단 분포에 따라 반복적인 과정올 통해 조정해 가는 추정방법이다. 그러나 특정한 표본 칸의 수가 0 인 경우 수렴하지 않을 수 있다는 단점을 지니고 있지만, 이러한 단점만 피할 수 있다 면, 충분히 효율적인 추정이 된다(Oh 와 Schuren,1987). 이와 더불어 래킹비 추정을 적용할 때, 만 일 분할표상의 한 변수의 모집단 주변수 총합은 알고 있지만, 다른 변수는 그렇지 않을 경우 래킹 비 추정과정을 적용할 수 없다는 제한적인 면이 있다. 
본 논문에서는 이와 같은 문제점을 해결하고자 표본자료로부터 얻은 분할표에 대해 행(또는 열) 변수의 모집단 주변수 총합과 다른 변수간의 결합을 통해 의사-열(또는 행)의 주변 수 총합을 구 한 후, 최종적으로 표본칸수를 조정하는 과정을 제안하였으며, 실제 자료와 모의 자료를 퉁해 제 안된 추정과정이 적절함올 보였다.

\section{참고문헌}

[1] Brackstone, G. J., and Rao, J. N. K.(1979), An investigation of raking ratio estimators, Sankhya, C, Vol. 41, 97-114.

[2] Buskirk, T. D.and Meza, J. L.(2003), A Post-stratified Raking-ratio Estimator Linking National and State Survey Data for Estimating Drug Use, Journal of Official Statistics, Vol. 19, 237-252.

[3] Causey, B. D.(1972), Sensitivity of Raked Contingency Table Totals to Changes in Problem Conditions, Annals of Mathematical Statistics, Vol. 43, 656-658.

[4] Cochran, W. G.(1977), Sampling Techniques 3rd ed. New York, John Wiley \& Sons.

[5] Deming, W.E.,and Stephan, F.F.(1940), On at least square adjustment of sampled frequency table when the expected marginal totals are known, Anals of Mathematical Statistics, Vol. 11, 427-444.

[6] Deville, J.C., and Sarndal, C.E.(1992),Calibration estimators in survey sampling, Journal of the American Statistical Association, 87, 376-382.

[7] Kalton, G., and Cervantes, I. F.(2003), Weighting Methods, Journal of Official Statistics, Vol. 19, 2, 81-97.

[8] Lohr, S.L.(1999), Sampling: Design and Analysis. Brooks/Cole Publishing Company; Pacific Grove, CA.

[9] Lu. H., and Gelman, A.(2003), A Method for Estimating Design-based Sampling Variances for Surveys with Weighting, Poststratification, and Raking, Journal of Official Statistics, Vol. 19, 133-151.

[10] Sarndal, C.E., Swensson, B., and Wretman, J.(1992), Model Assisted Survey Sampling, New York, Springer-Verlag.

[11] SAS IML User's Guide. SAS Institute.

[12] Wright, D., Gfroerer, J.,and Epstein, J.(1997), Ratio Estimation of Hard-Core Drug Use. Journal of Official Statistics, Vol. 13, 401-416.

[ 2003년 11월 접수, 2004년 7월 채택 ] 


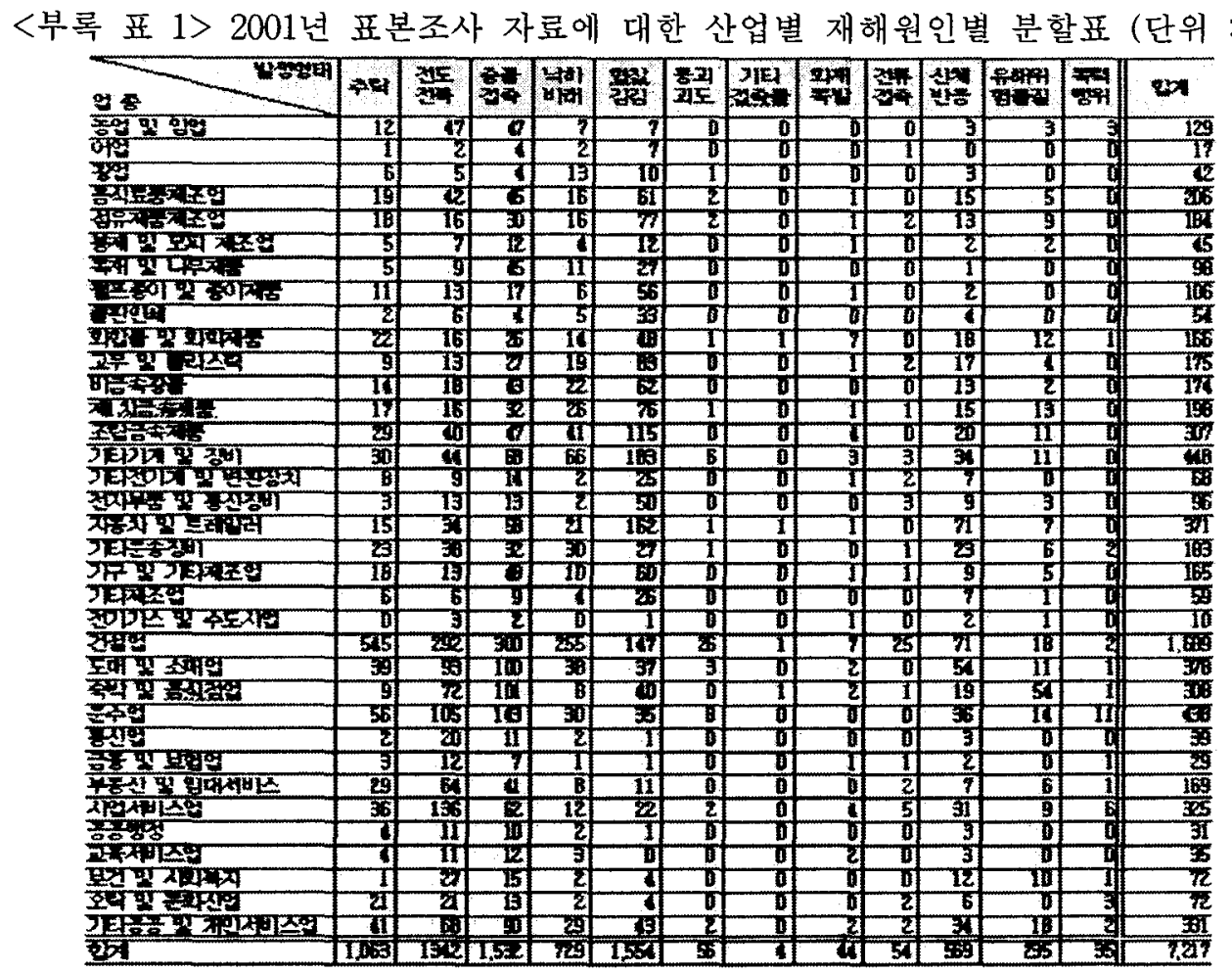

명)

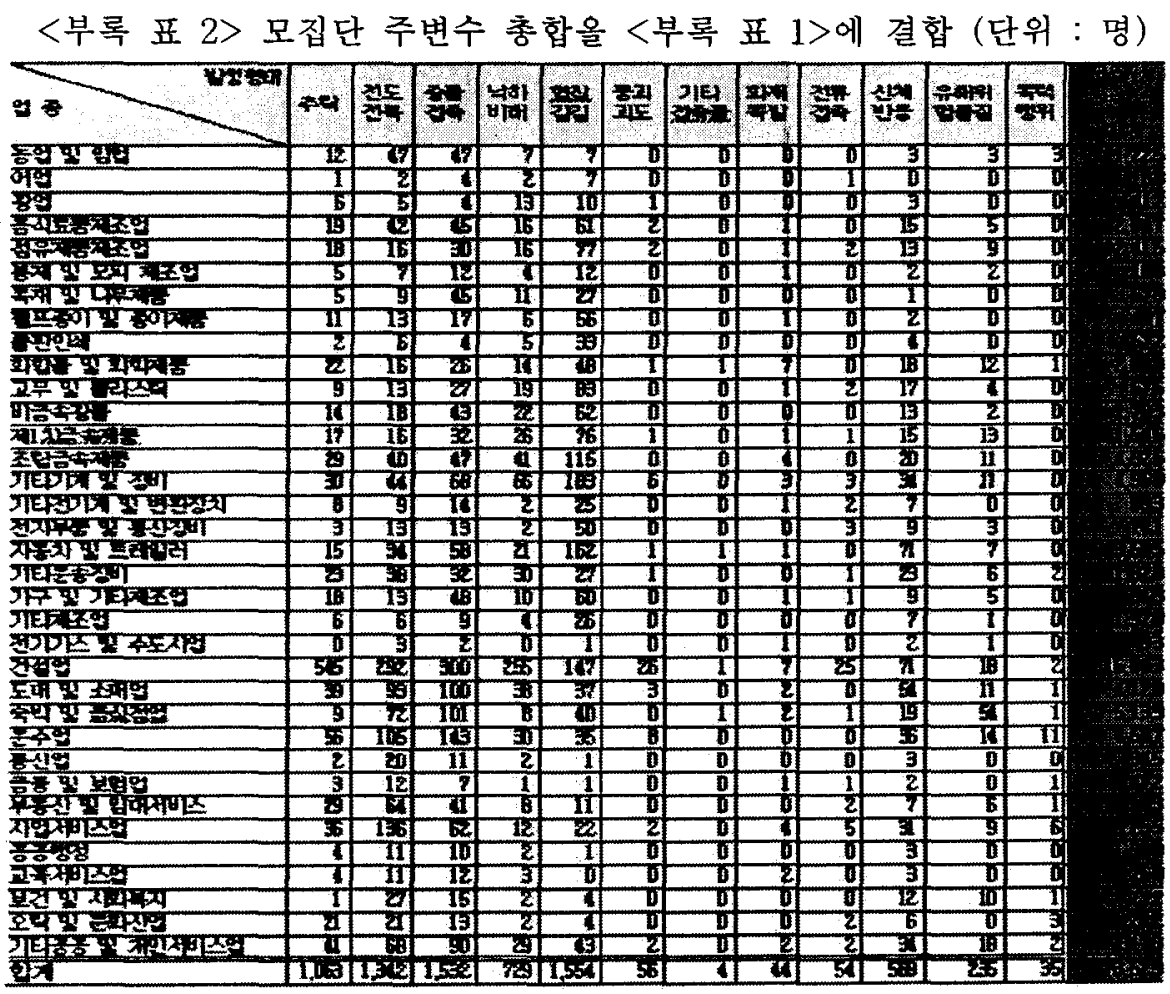




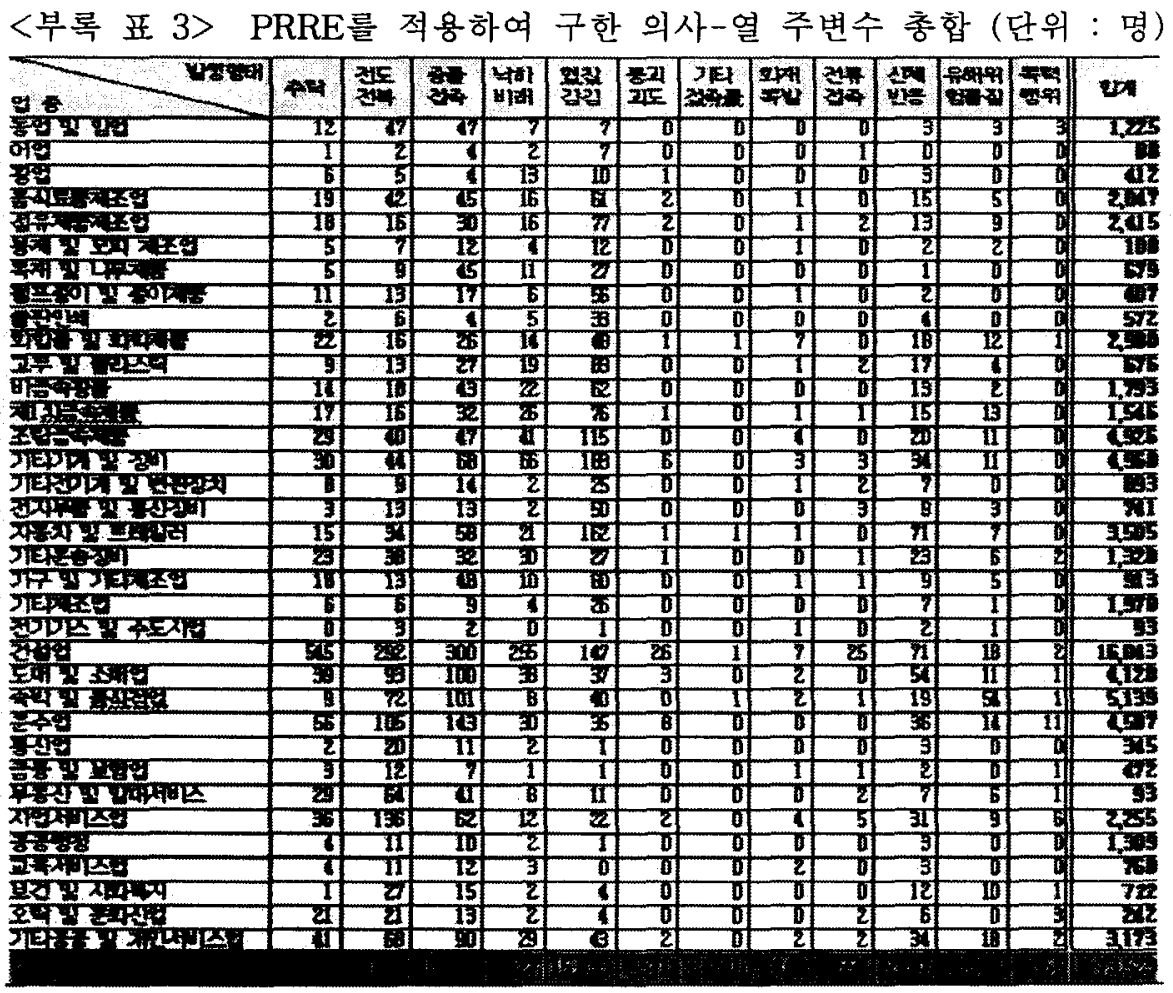

<부록 표 4> 추정된 모집단 간수 (단위 : 명)

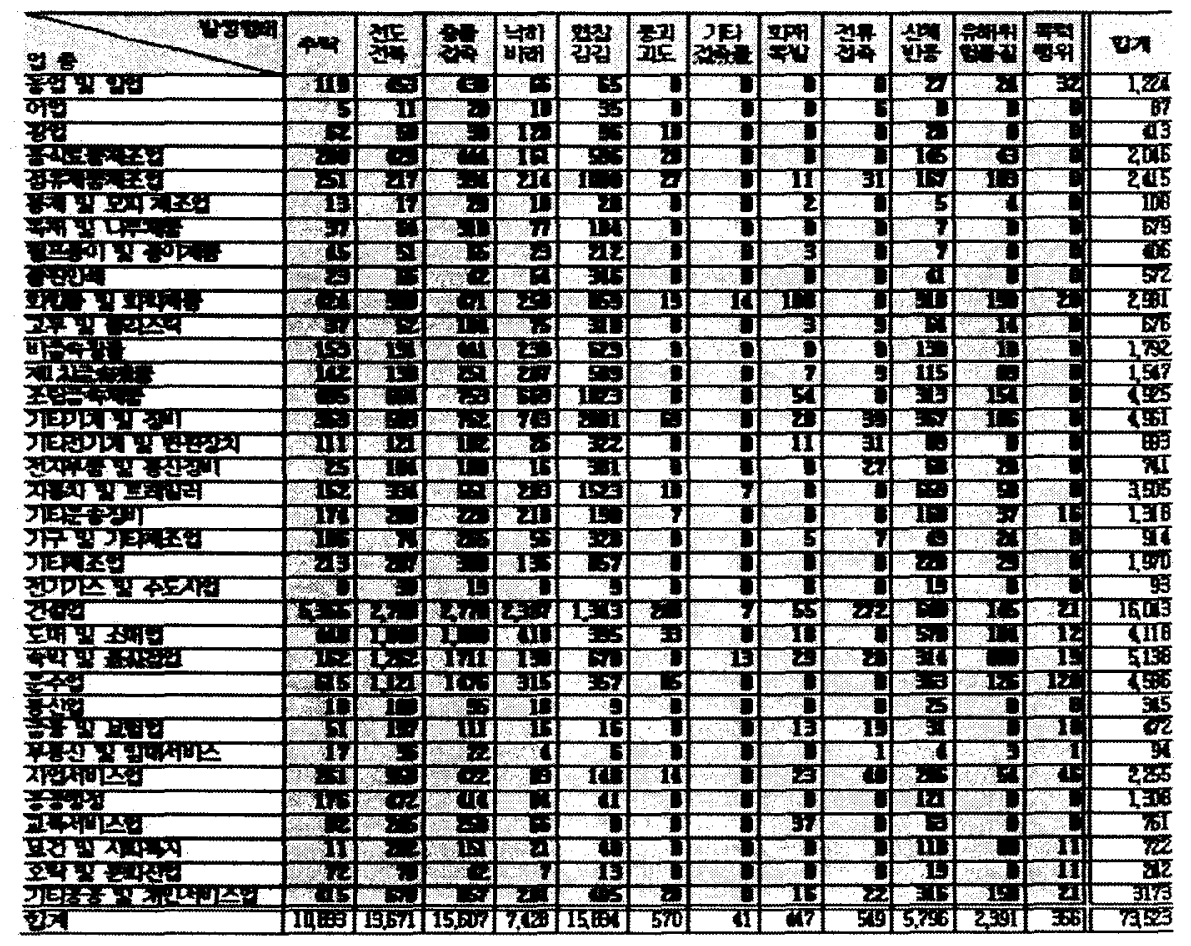

